\title{
Optimum heating of cylindrical pressure vessels
}

\author{
P. Dzierwa ${ }^{1} \cdot$ D. Taler ${ }^{1} \cdot$ J. Taler ${ }^{2}$
}

Received: 4 November 2014 / Published online: 15 March 2016

(C) The Author(s) 2016. This article is published with open access at Springerlink.com

\begin{abstract}
A method for determining time-optimum fluid temperature changes during heating of the thick walled cylinder was presented. Optimum fluid temperature changes were determined both for the cylindrical pressure vessels without holes. Heating of the hollow cylinder will be carried out in such a way that the circumferential thermal stress at the inner surface is equal to the allowable stress value. Optimum fluid temperature changes were assumed in the form of simple time functions containing unknown parameters. The unknown parameters were determined from the condition that the circumferential thermal stress at the inner surface of the hollow cylinder without holes is equal to the allowable stress at given time points. An over-determined system of nonlinear algebraic equations was solved for unknown parameters using the least squares method. At first, the thermal stress was calculated using the discrete form of the Duhamel integral. The Finite Element Method (FEM) was used to determine the circumferential thermal stress in the second method. For practical reasons the optimum temperature in the ramp form is preferred. It is possible to increase the fluid temperature stepwise at the beginning of the heating process and then increase the fluid temperature
\end{abstract}

The research presented in this paper has been partially funded by the National Science Centre-Project No. 3239/B/T02/2011/40.

\footnotetext{
$\triangle$ J. Taler

taler@mech.pk.edu.pl

Institute of Thermal Power Engineering,

Faculty of Mechanical Engineering,

Cracow University of Technology,

Al. Jana Pawła II 37, 31-864 Cracow, Poland

2 Institute of Thermal Engineering and Air Protection, Faculty of Environmental Engineering,

Cracow University of Technology,

ul. Warszawska 24, 31-155 Cracow, Poland
}

with the constant rate. Because of the possibility of practical implementation a more appropriate is the ramp function for approximating optimum fluid temperature changes.

\section{Optimierte Erwärmung zylindrischer Druckbehälter}

Zusammenfassung Ein Verfahren zum Bestimmen der zeitoptimalen Fluid Temperaturänderungen während der Aufheizung des dickwandigen Zylinders wurde dargestellt. Optimale Fluidtemperatur - Änderungen wurden für den zylindrischen Druckbehälter ohne Löcher bestimmt. Das Erhitzen des Hohlzylinders erfolgt in der Weise, dass die thermische Umfangsspannung an der inneren Oberfläche gleich dem zulässigen Wert ist. Optimale Fluidtemperatur - Änderungen wurden in der Form von einfachen Zeitfunktionen mit unbekannten Parametern angenommen. Die unbekannten Parameter wurden aus der Bedingung, daß die thermische Umfangsspannung an der inneren Zylinderoberfläche bei gegebenen Zeitpunkten gleich der zulässigen Spannung ist. Ein überbestimmtes System von nichtlinearen algebraischen Gleichungen wurde für unbekannte Parameter mit Hilfe der Methode der kleinsten Quadrate gelöst. Zuerst wurde die thermische Spannung anhand der diskreten Form des Duhamelschen Integrals berechnet. In dem zweiten Verfahren wurde die Finite-ElementeMethode (FEM) verwendet, um die tangentiale thermische Spannung zu bestimmen. Aus praktischen Gründen ist der rampenförmige optimale Temperaturverlauf bevorzugt. Es ist möglich zu Beginn des Aufheizvorgangs die Fluidtemperatur stufenweise zu erhöhen und dann die Temperatur der Flüssigkeit mit der konstanten Geschwindigkeit zu erheben. Aufgrund der Möglichkeit der praktischen Umsetzung ist eine rampenförmige Funktion zur Annäherung der optimalen Fluid -Temperaturänderungen sehr geeignet. 


\section{List of symbols}

\begin{tabular}{|c|c|}
\hline$a=\lambda /(c \rho)$ & Thermal diffusivity, $\mathrm{m}^{2} / \mathrm{s}$ \\
\hline$B i=\alpha r_{i n} / \lambda$ & Biot number \\
\hline $\mathrm{c}$ & Specific heat capacity, $J /(\mathrm{kgK})$ \\
\hline $\mathrm{E}$ & Modulus of elasticity, $\mathrm{MPa}$ \\
\hline $\mathrm{f}$ & $\begin{array}{l}\text { Excess fluid temperature above the initial } \\
\text { temperature, }{ }^{\circ} \mathrm{C}\end{array}$ \\
\hline$F o=a t / r_{i n}^{2}$ & Fourier number \\
\hline$k_{o}=r_{o} / r_{\text {in }}$ & Ratio of outer to inner radius \\
\hline $\mathrm{p}$ & Absolute pressure, $\mathrm{MPa}$ \\
\hline $\mathrm{p}_{\mathrm{o}}$ & Atmospheric pressure, $\mathrm{MPa}$ \\
\hline $\mathrm{r}$ & Radius, $\mathrm{m}$ \\
\hline$r_{o}, r_{\text {in }}$ & Outer and inner radius of the vessel, $\mathrm{m}$ \\
\hline $\mathrm{r}, \varphi, \mathrm{z}$ & Cylindrical coordinates \\
\hline $\mathbf{r}_{\mathrm{P}}$ & $\begin{array}{l}\text { Position vector of a point } \mathrm{P} \text { on the edge of the } \\
\text { hole }\end{array}$ \\
\hline $\mathrm{R}=\mathrm{r} / \mathrm{r}_{\mathrm{in}}$ & Dimensionless radius \\
\hline $\mathrm{s}$ & Wall thickness, $\mathrm{m}$ \\
\hline $\mathrm{t}$ & Time, $\mathrm{s}$ \\
\hline $\mathrm{T}$ & Temperature, ${ }^{\circ} \mathrm{C}$ \\
\hline $\mathrm{T}_{\mathrm{f}}$ & Fluid temperature, ${ }^{\circ} \mathrm{C}$ \\
\hline $\bar{T}$ & Mean temperature over the wall thickness, ${ }^{\circ} \mathrm{C}$ \\
\hline $\mathrm{u}_{\mathrm{T}}$ & Influence function for temperature \\
\hline $\mathrm{u}_{\mathrm{N}}$ & $\begin{array}{l}\text { Influence function for circumferential stress, } \\
\mathrm{MPa} / \mathrm{K}\end{array}$ \\
\hline $\mathrm{v}_{\mathrm{T}}$ & Rate of temperature changes, $\mathrm{K} / \mathrm{s}$ \\
\hline$\alpha$ & Heat transfer coefficient, $\mathrm{W} /\left(\mathrm{m}^{2} \mathrm{~K}\right)$ \\
\hline$\alpha_{\mathrm{m}}$ & $\begin{array}{l}\text { Stress concentration factor for circumferential } \\
\text { stress caused by pressure at point } \mathrm{P} \text { on the edge } \\
\text { of the hole }\end{array}$ \\
\hline$\beta$ & Linear thermal expansion coefficient, $1 / \mathrm{K}$ \\
\hline$\Delta t$ & Time step, $\mathrm{s}$ \\
\hline$\lambda$ & Thermal conductivity, $\mathrm{W} /(\mathrm{mK})$ \\
\hline$\mu_{n}$ & nth root of characteristic equation \\
\hline$v$ & Poisson's ratio \\
\hline$\rho$ & Density, $\mathrm{kg} / \mathrm{m}^{3}$ \\
\hline$\sigma$ & Normal stress, $\mathrm{MPa}$ \\
\hline$\sigma_{a}$ & Allowable stress, $\mathrm{MPa}$ \\
\hline$\sigma_{e}$ & Equivalent stress, $\mathrm{MPa}$ \\
\hline$\sigma_{p, r}, \sigma_{p, \varphi}, \sigma_{p, z}$ & $\begin{array}{l}\text { Radial, circumferential and axial component of } \\
\text { the stress due to pressure, } \mathrm{MPa}\end{array}$ \\
\hline$\sigma_{\mathrm{T}, \mathrm{r}}, \sigma_{\mathrm{T}, \varphi}, \sigma_{\mathrm{T}, \mathrm{z}}$ & $\begin{array}{l}\text { Radial, circumferential and axial thermal stress } \\
\text { component, } \mathrm{MPa}\end{array}$ \\
\hline
\end{tabular}

\section{Introduction}

Optimization of heating and cooling of thick boiler components is the subject of many studies [1-6], since too rapid heating or cooling element causes high thermal stresses.

There is a great need for reducing start-up and shut-down costs in thermal power plants. The main motivation is the new demand caused by a deregulated electricity market where more frequent and shorter start-ups and shut-downs are necessary in order to realize the short-term power requests from the electrical load dispatcher [4]. Fast start-up and shutdown of the power units are desired to reduce fuel oil consumption during start-up and to decrease emissions of pollutants into the atmosphere.

The major limiting factor relevant to fast power plant start-ups is maximum allowable thermal stress for thickwalled components such as headers of superheaters and reheaters, boiler drums and steam turbine rotors. Any exceeding of the stress limit reduces lifetime of these components. The new control system proposed by Krüger et al. [4] aims at improving of the start-up procedures of boilers and explicitly takes the thermal stress values of critical components into account.

Taking into account the increasing share of wind farms in the production of electricity, combined - cycle gas and steam power plants must be quickly activated to supply the missing electrical energy into the power system when the wind velocity drops. The heat recovery steam generator (HRSG) is a critical element limiting fast start-up of the gas and steam power units. During the start-up period, HRSG components, especially the drum, are subject to high thermal stresses, which are caused by the non-uniform temperature distribution over the component wall thickness. To avoid excessive thermal stresses in the boiler drum, the flue gas exiting a gas turbine flows directly to the chimney bypassing the HRSG [6]. It makes possible to deliver electricity to the grid at the expense of low efficiency of the gas and steam unit. The gas bypass is open during the initial stage of the start-up. Estimation of the maximum thermal stress enables the optimization of the bypass mode [6]. In both papers drum is considered as a thick-walled cylinder in which the temperature distribution is a function of radius and time [4-5].

Allowable heating rates of thick-walled boiler pressure components are calculated in engineering practice using European Standard [7] which is based on the quasi-steady state temperature distribution inside the pressure element. Quasi steady state temperature distribution is formed in the thick-walled element after heating it at a constant rate for a long time [8].

Haneke and Speitkamp [9] determined approximate optimum fluid temperature changes and the optimum thickness of the thick-walled pressure vessels. They considered thick-walled pressure elements with openings. The optimum changes of the fluid temperature was approximated by a piecewise linear function.

A method of determining the optimum time changes of fluid temperature during heating process of boiler structural pressure elements was proposed in [10]. The optimization procedure is based on the discrete form of the Duhamel's integral. 
Another method for optimum heating of thick walled pressure components was presented in [11, 12]. Allowing stepwise fluid temperature increase at the beginning of heating, the allowable heating rates were calculated according to the EN 12952-3 European Standard: $v_{T 1}$ for the initial pressure $p_{1}$ and $v_{T 2}$ for the final pressure $p_{2}$.

Optimum heating of the thick walled plate is the subject of the paper by Taler [13]. A linear inverse heat conduction problem was solved using various methods when linear time temperature variation is prescribed at the insulated rear surface of the plate. Physical properties of plate material were assumed to be constant.

The paper presents a new method of determining the optimum fluid temperature changes during heating of thick walled hollow cylinders. Optimum temperature curve for a hollow cylinder without holes will be determined from the condition that the von Mises equivalent stress at the cylinder inner surface is equal to the permissible stress.

\section{Optimum heating of cylindrical vessel}

Optimum heating of a long hollow cylinder with free ends will be analyzed. Three thermal stress components, radial $\sigma_{T, r}$, circumferential $\sigma_{T, \varphi}$, and axial $\sigma_{T, z}$ are given by $[14,15]$

$$
\begin{gathered}
\sigma_{T, r}=\frac{E \beta}{2(1-v)}\left(1-\frac{r_{i n}^{2}}{r^{2}}\right)\left[T_{m}(t)-T_{r, m}(r, t)\right] \\
\sigma_{T, \varphi}=\frac{E \beta}{2(1-v)}\left[\left(1+\frac{r_{i n}^{2}}{r^{2}}\right) T_{m}(t)+\left(1-\frac{r_{i n}^{2}}{r^{2}}\right) T_{r, m}(r, t)-2 T(r, t)\right] \\
\sigma_{T, z}=\frac{E \beta}{1-v}\left[T_{m}(t)-T_{r, m}(r, t)\right]
\end{gathered}
$$

where the mean temperatures $T_{r, m}(r, t)$ and $T_{m}(t)$ are given by

$$
\begin{gathered}
T_{r, m}(r, t)=\frac{2}{r^{2}-r_{i n}^{2}} \int_{r_{\text {in }}}^{r} T r d r \\
T_{m}(t)=\frac{2}{r_{o}^{2}-r_{i n}^{2}} \int_{r_{\text {in }}}^{r_{o}} T r d r
\end{gathered}
$$

The stress components in a thick walled cylinder under internal pressure loading are $[14,18]$

$$
\sigma_{p, r}=-\left(p-p_{o}\right) \frac{\left(\frac{r_{o}}{r}\right)^{2}-1}{\left(\frac{r_{o}}{r_{i n}}\right)^{2}-1}
$$

$$
\begin{gathered}
\sigma_{p, \varphi}=\left(p-p_{o}\right) \frac{\left(\frac{r_{o}}{r}\right)^{2}+1}{\left(\frac{r_{o}}{r_{i n}}\right)^{2}-1} \\
\sigma_{p, z}=\left(p-p_{o}\right) \frac{1}{\left(\frac{r_{o}}{r_{i n}}\right)^{2}-1}
\end{gathered}
$$

Equations (1-8) were derived assuming the elastic state of stress and constant physical properties which are independent of the position and temperature. The cylinder wall temperature varies only in the radial direction while in the axial and circumferential directions remains constant. For the flow of steam, hot water or other fluids changes of temperature in the axial direction are small compared to the radial direction. Non-uniformity of the temperature on the perimeter of the cylindrical vessel occurs only for steam condensation or stratified flow in the horizontal vessels. The equivalent stress at the inner surface of the cylinder is calculated according to the Maxwell-Huber-Hencky-von Mises theory as follows

$\sigma_{e}=\sigma_{\max }-\sigma_{\min }=\left(\left.\sigma_{T, r}\right|_{r=r_{\text {in }}}+\left.\sigma_{p, r}\right|_{r=r_{\text {in }}}\right)-\left(\left.\sigma_{T, \varphi}\right|_{r=r_{\text {in }}}+\left.\sigma_{p, \varphi}\right|_{r=r_{\text {in }}}\right)(9)$

Substituting Equations: (1), (6), (2), and (7) for $r=r_{i n}$ into (9) gives

$\sigma_{e}=\sigma_{\max }-\sigma_{\min }=-\left(p-p_{o}\right)\left(1+\frac{r_{o}^{2}+r_{i n}^{2}}{r_{o}^{2}-r_{i n}^{2}}\right)-\frac{E \beta}{1-v}\left(T_{m}-\left.T\right|_{r=r_{i n}}\right)$

If fluid temperature $f(t)$ is time dependent, the temperature $T\left(r_{i n}, t\right)$ and the circumferential stress $\sigma_{T, \varphi}\left(r_{i n}, t\right)$ at the cylinder inner surface will be calculated using the Duhamel integral $[16,17]$

$$
\begin{gathered}
T\left(r_{i n}, t\right)=\int_{0}^{t} f(\theta) \frac{\partial u_{T}\left(r_{i n}, t-\theta\right)}{\partial t} d \theta \\
\sigma_{T, \varphi}\left(r_{i n}, t\right)=\int_{0}^{t} f(\theta) \frac{\partial u_{S}\left(r_{i n}, t-\theta\right)}{\partial t} d \theta
\end{gathered}
$$

where $f(t)=T_{f}(t)-T_{0}$ designates time dependent fluid excess temperature. The initial temperature $T_{0}$, is assumed to be uniform.

Equations (11) and (12) are based on the superposition principle, which in turn can be used for solving linear problems. This means that the material properties must be independent of temperature. 
The function $u_{T}\left(r_{i n}, t\right)$ is a solution of the initial boundary problem at the surface $r=r_{i n}$, for a unit step function, $f(t)=1, t>0$. This function is also called an influence function. The function $u_{S}\left(r_{i n}, t\right)$ represents time changes of the circumferential thermal stress component at the inner surface $r=r_{i n}$ caused by the unit stepwise increase in the fluid temperature for $t>0$.

Time changes in the fluid temperature are approximated by a stepwise function (Fig. 1)

$$
\begin{array}{cc}
f_{1}=f\left(\theta_{1} / 2\right) & 0 \leq t \leq \theta_{1}, \\
f_{2}=f\left[\theta_{1}+\left(\theta_{2}-\theta_{1}\right) / 2\right] & \theta_{1} \leq t \leq \theta_{2}, \\
\vdots & \\
f_{i}=f\left[\theta_{i-1}+\left(\theta_{i}-\theta_{i-1}\right) / 2\right] & \theta_{i-1} \leq t \leq \theta_{i}, \\
\vdots & \\
f_{M}=f\left[\theta_{M-1}+\left(\theta_{M}-\theta_{M-1}\right) / 2\right] & \theta_{M-1} \leq t \leq \theta_{M} .
\end{array}
$$

Coordinates of the points in time $\theta_{i}$ are given by

$$
\theta_{i}=\theta_{i-1}+\Delta \theta_{i}, i=1, \ldots, M
$$

where $\theta_{0}=0$.

If time steps $\Delta \theta_{i}$ are constant and equal $\Delta \theta=t_{M} / M$ then

$$
\theta_{i}=i \Delta \theta, i=0, \ldots, M
$$

Using the method of rectangles, the integral in the formula (1) for temperature at time $t_{M}$ gives

$$
\begin{gathered}
T\left(r_{i n}, t_{M}\right)=\sum_{i=1}^{M} f_{i} \frac{u_{T}\left(r_{i n}, t_{M}-\theta_{i-1}\right)-u_{T}\left(r_{i n}, t_{M}-\theta_{i}\right)}{\Delta t_{i}} \Delta \theta_{i} \\
\sum_{i=1}^{M} f_{i}\left[u_{T}\left(r_{i n}, t_{M}-\theta_{i-1}\right)-u_{T}\left(r_{i n}, t_{M}-\theta_{i}\right)\right]= \\
=f_{1}\left[u_{T}\left(r_{i n}, t_{M}-\theta_{0}\right)-u_{T}\left(r_{i n}, t_{M}-\theta_{1}\right)\right]+ \\
f_{2}\left[u_{T}\left(r_{i n}, t_{M}-\theta_{1}\right)-u_{T}\left(r_{i n}, t_{M}-\theta_{2}\right)\right]+ \\
\vdots \\
f_{M}\left[u_{T}\left(r_{i n}, t_{M}-\theta_{M-1}\right)-u_{T}\left(r_{i n}, t_{M}-\theta_{M}\right)\right]
\end{gathered}
$$

where $\theta_{0}=0$ and $u\left(r_{i n}, t_{M}-\theta_{M}\right)=u\left(r_{i n}, 0\right)=0$.

The symbol $T\left(r_{i n}, t_{M}\right)$ designates the wall temperature excess above the initial temperature $T_{0}$ which is constant through the thickness of the cylinder wall. Circumferential stresses $\sigma_{T, \varphi}\left(r_{i n}, t_{M}\right)$ are calculated in the same way as the temperature $T\left(r_{i n}, t_{M}\right)$. To determine the influence function $u_{S}\left(r_{i n}, t_{M}\right)$ for circumferential thermal stresses, the influence function $u_{T}\left(r_{i n}, t_{M}\right)$ for the wall temperature, must be found at first. If we assume that the cylinder outer surface is thermally insulated (Fig. 2), then the influence function $u_{T}(r, t)$ is given by:

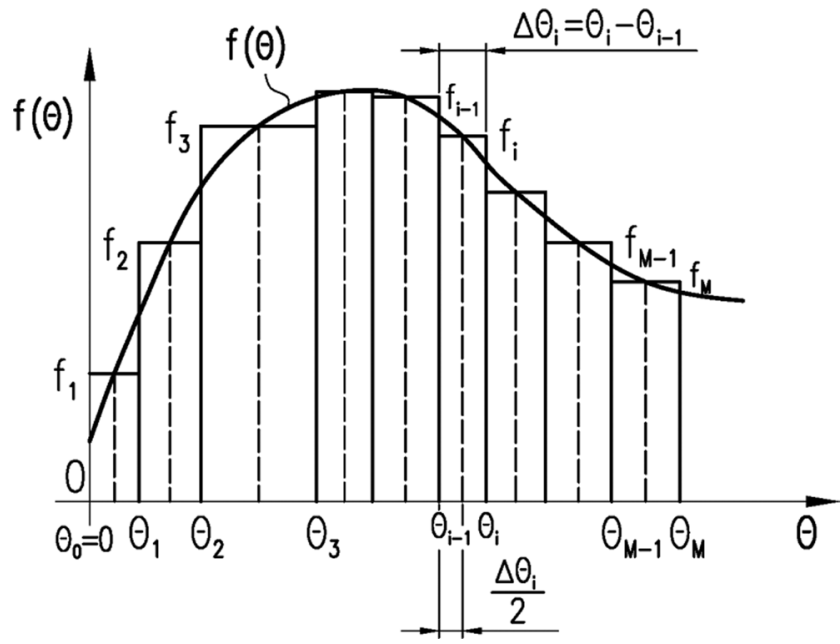

Fig. 1 Stepwise approximation of fluid temperature changes

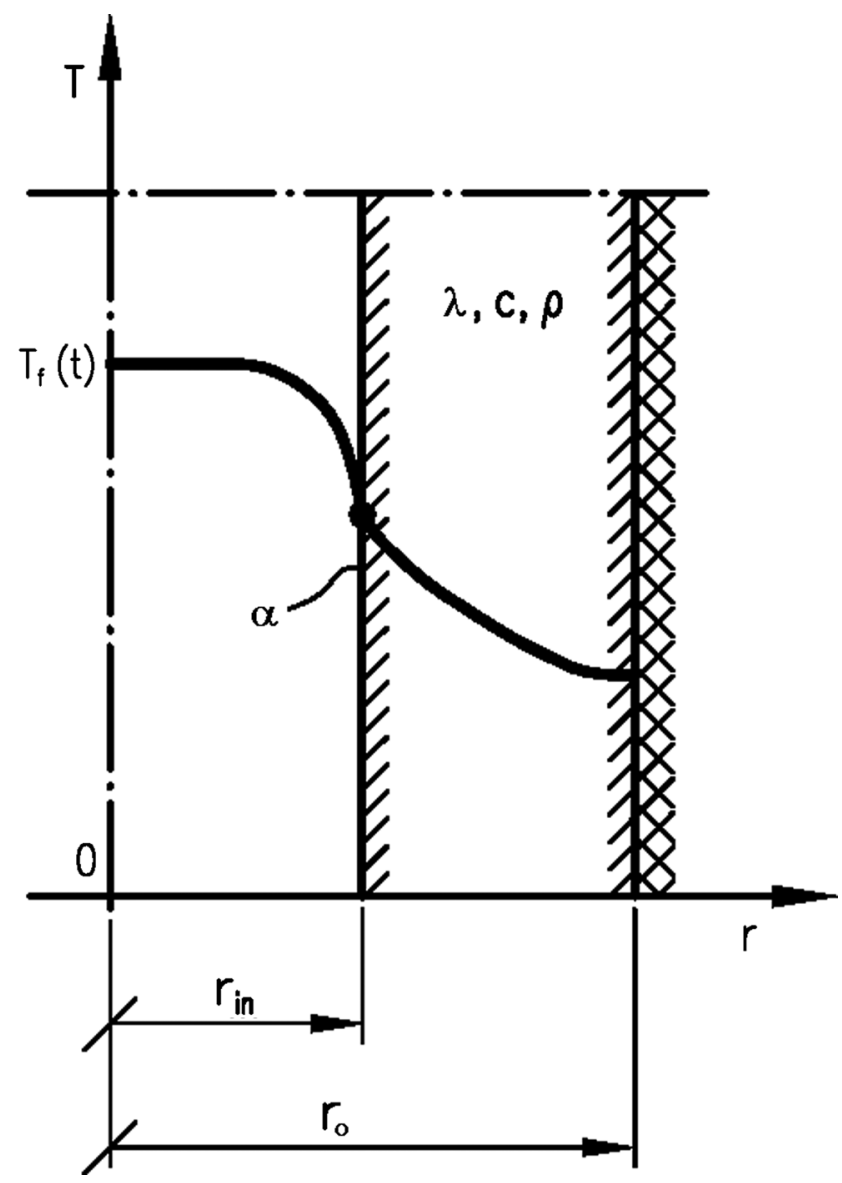

Fig. 2 Infinite hollow cylinder with insulated outer surface and convective heat transfer at the inner surface

$$
\frac{\partial u_{T}}{\partial F_{o}}=\frac{1}{R} \frac{\partial}{\partial R}\left(R \frac{\partial u_{T}}{\partial R}\right), \quad 1 \leq R \leq k_{o}
$$

for the following boundary and initial conditions 


$$
\begin{gathered}
-\left.\frac{\partial u_{T}}{\partial R}\right|_{R=1}=B i\left(1-\left.u_{T}\right|_{R=1}\right) \\
\left.\frac{\partial u_{T}}{\partial R}\right|_{R=k}=0 \\
\left.u_{T}\right|_{F o=0}=0
\end{gathered}
$$

Here $B i=\alpha r_{\text {in }} / \lambda$ denotes the Biot number, $k_{o}=r_{o} / r_{i n}$ is the ratio of the outer to inner radius, $F_{O}=a t / r_{i n}^{2}$ the Fourier number, and $R=r / r_{i n}$.

The solution of the initial-boundary problem (17-20) is [16-19]

$$
u_{T}=1-\sum_{n=1}^{\infty} D_{n} P_{n} \exp \left(-\mu_{n}^{2} F o\right)
$$

where

$$
\begin{gathered}
D_{n}=\frac{\pi \frac{B i}{\mu_{n}}\left[J_{1}\left(\mu_{n}\right)+\frac{B i}{\mu_{n}} J_{0}\left(\mu_{n}\right)\right]}{\left[J_{1}\left(\mu_{n}\right)+\frac{B i}{\mu_{n}} J_{0}\left(\mu_{n}\right)\right]^{2}-\left[1+\left(\frac{B i}{\mu_{n}}\right)^{2}\right] J_{1}\left(k_{o} \mu_{n}\right)} \\
P_{n}=J_{1}\left(k_{o} \mu_{n}\right) Y_{0}\left(R \mu_{n}\right)-Y_{1}\left(k_{o} \mu_{n}\right) J_{0}\left(R \mu_{n}\right)
\end{gathered}
$$

The roots $\mu_{n}$ are determined from the solution of the following characteristic equation

$$
\begin{gathered}
\frac{Y_{1}\left(k_{o} \mu\right)}{J_{1}\left(k_{o} \mu\right)} \cdot \frac{J_{1}(\mu)+\frac{B i}{\mu} J_{0}(\mu)}{Y_{1}(\mu)+\frac{B i}{\mu} Y_{0}(\mu)}=1 \\
J_{0}(\mu) Y_{1}\left(k_{o} \mu\right)-J_{1}\left(k_{o} \mu\right) Y_{0}(\mu)=0, \text { for } B i \rightarrow \infty
\end{gathered}
$$

where $J_{0}$ and $J_{1}$ are the zero and first order Bessel functions of the first kind, $Y_{0}$ and $Y_{1}$ are the zero and first order Bessel functions of the second kind. The first ten roots of the characteristic equations (24) and (25) for selected values of the ratio $k_{0}$ are shown in Tables 1 and 2 respectively. The roots listed in Tables 1 and 2 were obtained by solving transcendental equations by the Müller root-finding algorithm [20, 21]. The circumferential stress in the hollow cylinder with free ends due to unit stepwise increase in fluid temperature is given by

$$
u_{N}=u_{N}(R, F O)=\frac{E \beta}{1-\nu}\left[\bar{u}_{T}-u_{T}\right]
$$

where $\bar{u}_{T}$ is the average temperature over the wall thickness which is defined as

$$
\bar{u}_{T}=\frac{2}{k_{o}^{2}-1} \int_{1}^{k_{o}} R u_{T} d R
$$

Substituting expression (21) into equations (27) and (26) gives

$$
\begin{aligned}
u_{N}= & \frac{E \beta}{1-\nu} \sum_{n=1}^{\infty} D_{n} \\
& \left\{\frac{2}{\left(k_{o}^{2}-1\right) \mu_{n}}\left[J_{1}\left(\mu_{n}\right) Y_{1}\left(k_{o} \mu_{n}\right)-J_{1}\left(k_{o} \mu_{n}\right) Y_{1}\left(\mu_{n}\right)\right]-P_{n}\right\} \\
& \exp \left(-\mu_{n}^{2} F o\right)
\end{aligned}
$$

If the ends of the hollow cylinder are free, axial and circumferential stresses at the inner as well as at the outer surface are equal. The previous optimization studies show $[10,11]$ that the optimum fluid temperature changes $T_{f}(t)$ obtained from the solution of the Volterra integral equation of the first kind, can be well approximated

$$
T_{f}=T_{0}+a+b t+c / t
$$

where: $T_{0}$-initial fluid temperature, $a, b, c,-$ constants, $t$-time.

At first, the optimum fluid temperature changes are approximated by the ramp function $T_{f}(t)$ (Fig. 2)

$$
T_{f}=T_{0}+a+b t
$$

which can easily be carried out in practice. The symbols in Eq. (30) stand for: $a$-initial stepwise temperature increase, $b$ - constant rate of fluid temperature changes. The optimum values of parameters $a, b$ and $c$ appearing in the function (29) or the parameters $a$ and $b$ in the function (30) will be determined from the condition

$$
\sigma_{e}\left(r_{i n}, t_{i}\right) \cong \sigma_{a}, \quad i=1, \ldots, n_{t}
$$

where: $\sigma_{e}\left(r_{i n}, t_{i}\right)$ - the equivalent von Misses stress at the inner surface, $r_{i n}$-inner radius of the cylinder, $t_{i}-i$-th time point, $n_{t}$-number of time points in the analyzed period of time, $\sigma_{a}$-allowable stress determined using current standards.

The overdetermined system of nonlinear algebraic eqations (31) was solved using the least squares method. Optimum values of searched parameters $a$ and $b$ or $a, b$, and $c$ were determined from the condition:

$$
\sum_{i=1}^{n_{t}}\left[\sigma_{e}\left(r_{i n}, t_{i}\right)-\sigma_{a}\right]^{2}=\min
$$

by the Levenberg Marquardt method [21].

If the pressure $p$ inside the cylinder is equal to the ambient pressure $p_{o}$, condition (9) simplifies to the form 
Table 1 Roots $\mu_{n}$ of characteristic equation (24)

\begin{tabular}{|c|c|c|c|c|c|c|c|}
\hline \multirow[t]{2}{*}{$\overline{\mu_{i}}$} & ${ }_{P i-} \alpha r_{i n}$ & $k_{o}=r_{o} / r_{i n}$ & & & & & \\
\hline & $B l=\frac{1}{\lambda}$ & 1.1 & 1.2 & 1.4 & 1.6 & 1.8 & 2.0 \\
\hline \multirow[t]{6}{*}{$\mu_{1}$} & 5 & 6.37638 & 4.10599 & 2.47154 & 1.76594 & 1.36587 & 1.10791 \\
\hline & 10 & 8.39980 & 5.14618 & 2.91462 & 2.01227 & 1.52320 & 1.21751 \\
\hline & 20 & 10.52048 & 6.05539 & 3.23569 & 2.17535 & 1.62209 & 1.28414 \\
\hline & 40 & 12.36636 & 6.70752 & 3.43415 & 2.27039 & 1.67798 & 1.32110 \\
\hline & 60 & 13.20543 & 6.96755 & 3.50715 & 2.30438 & 1.69768 & 1.33401 \\
\hline & 80 & 13.68337 & 7.10697 & 3.54502 & 2.32182 & 1.70774 & 1.34058 \\
\hline \multirow[t]{6}{*}{$\mu_{2}$} & 5 & 32.92922 & 17.13285 & 9.10328 & 6.33122 & 4.89375 & 4.00241 \\
\hline & 10 & 34.25400 & 18.20306 & 9.80180 & 6.80585 & 5.23144 & 4.25264 \\
\hline & 20 & 36.41490 & 19.63103 & 10.50287 & 7.20663 & 5.48700 & 4.42866 \\
\hline & 40 & 39.30119 & 21.06000 & 11.02707 & 7.46956 & 5.65192 & 4.53201 \\
\hline & 60 & 41.04864 & 21.73637 & 11.23432 & 7.56607 & 5.70012 & 4.56900 \\
\hline & 80 & 42.18820 & 22.12187 & 11.34427 & 7.61815 & 5.72920 & 4.58783 \\
\hline \multirow[t]{6}{*}{$\mu_{3}$} & 5 & 63.62090 & 32.19391 & 16.45439 & 11.17975 & 8.52063 & 6.90908 \\
\hline & 10 & 64.37606 & 32.89418 & 17.03102 & 11.64286 & 8.89144 & 7.20806 \\
\hline & 20 & 65.78187 & 34.06045 & 17.79229 & 12.14851 & 9.24238 & 7.46245 \\
\hline & 40 & 68.12635 & 35.61035 & 18.50987 & 12.54142 & 9.48571 & 7.62667 \\
\hline & 60 & 69.89947 & 36.49580 & 18.82794 & 12.69782 & 9.57758 & 7.68687 \\
\hline & 80 & 71.23045 & 37.05379 & 19.00356 & 12.78057 & 9.62537 & 7.71789 \\
\hline \multirow[t]{6}{*}{$\mu_{4}$} & 5 & 94.77802 & 47.65324 & 24.08237 & 16.21607 & 12.27295 & 9.89978 \\
\hline & 10 & 95.29529 & 48.15190 & 24.53275 & 16.61106 & 12.61516 & 10.19375 \\
\hline & 20 & 96.29689 & 49.05829 & 25.23730 & 17.13050 & 13.00537 & 10.49233 \\
\hline & 40 & 98.11500 & 50.46198 & 26.02296 & 17.60819 & 13.31589 & 10.70771 \\
\hline & 60 & 99.65708 & 51.41329 & 26.42221 & 17.81495 & 13.44008 & 10.79000 \\
\hline & 80 & 100.93400 & 52.06524 & 26.65265 & 17.92723 & 13.50574 & 10.83289 \\
\hline \multirow[t]{6}{*}{$\mu_{5}$} & 5 & 126.06280 & 63.23115 & 31.81291 & 21.33624 & 16.09407 & 12.94375 \\
\hline & 10 & 126.45600 & 63.61534 & 32.17395 & 21.66819 & 16.39434 & 13.21489 \\
\hline & 20 & 127.22460 & 64.34005 & 32.78292 & 22.16086 & 16.78864 & 13.53039 \\
\hline & 40 & 128.67680 & 65.56509 & 33.58286 & 22.68388 & 17.14638 & 13.78623 \\
\hline & 60 & 129.98400 & 66.49017 & 34.03271 & 22.93186 & 17.29913 & 13.88890 \\
\hline & 80 & 131.13370 & 67.17609 & 34.30704 & 23.07070 & 17.38158 & 13.94317 \\
\hline \multirow[t]{6}{*}{$\mu_{6}$} & 5 & 157.39910 & 78.86008 & 39.59018 & 26.49795 & 19.94999 & 16.01900 \\
\hline & 10 & 157.71370 & 79.17117 & 39.88872 & 26.78024 & 20.21297 & 16.26187 \\
\hline & 20 & 158.33610 & 79.77008 & 40.50014 & 27.23302 & 20.59345 & 16.57964 \\
\hline & 40 & 159.53700 & 80.83500 & 41.18840 & 27.77437 & 20.98098 & 16.86550 \\
\hline & 60 & 160.64770 & 81.69999 & 41.66551 & 28.05286 & 21.15813 & 16.98655 \\
\hline & 80 & 161.67060 & 82.37418 & 41.97190 & 28.21477 & 21.25608 & 17.05163 \\
\hline \multirow[t]{6}{*}{$\mu_{7}$} & 5 & 188.76210 & 94.51521 & 47.39200 & 31.68345 & 23.82800 & 19.11330 \\
\hline & 10 & 189.02550 & 94.77634 & 47.64553 & 31.90219 & 24.05884 & 19.33084 \\
\hline & 20 & 189.54830 & 95.28437 & 48.11044 & 32.33905 & 24.41809 & 19.64000 \\
\hline & 40 & 190.56510 & 96.21706 & 48.83464 & 32.87909 & 24.82126 & 19.94693 \\
\hline & 60 & 191.53080 & 97.01323 & 49.32102 & 33.18002 & 25.01856 & 20.08419 \\
\hline & 80 & 192.43330 & 97.67191 & 49.64924 & 33.36110 & 25.13056 & 20.15941 \\
\hline \multirow[t]{6}{*}{$\mu_{8}$} & 5 & 220.14010 & 110.18510 & 55.20803 & 36.88237 & 27.71896 & 22.21967 \\
\hline & 10 & 220.36640 & 110.41000 & 55.42818 & 37.09546 & 27.92383 & 22.41529 \\
\hline & 20 & 220.81630 & 110.85030 & 55.83986 & 37.46998 & 28.25860 & 22.71200 \\
\hline & 40 & 221.70000 & 111.67570 & 56.51490 & 37.99789 & 28.66784 & 23.03019 \\
\hline & 60 & 222.54500 & 112.40500 & 56.99776 & 38.31281 & 28.88121 & 23.18247 \\
\hline & 80 & 223.34980 & 113.03060 & 57.34000 & 38.51061 & 29.00571 & 23.26704 \\
\hline \multirow[t]{6}{*}{$\mu_{9}$} & 5 & 251.52800 & 125.86500 & 63.03399 & 42.08998 & 31.61800 & 25.33410 \\
\hline & 10 & 251.72600 & 126.06200 & 63.22772 & 42.27941 & 31.80141 & 25.51088 \\
\hline & 20 & 252.12000 & 126.45000 & 63.59597 & 42.62099 & 32.11295 & 25.79197 \\
\hline & 40 & 252.89410 & 127.19100 & 64.22296 & 43.13015 & 32.52084 & 26.11896 \\
\hline & 60 & 253.65050 & 127.85630 & 64.69708 & 43.44986 & 32.74650 & 26.28177 \\
\hline & 80 & 254.37380 & 128.44580 & 65.04505 & 43.66381 & 32.88197 & 26.37499 \\
\hline
\end{tabular}


Table 1 (continuation)

\begin{tabular}{llllllll}
\hline$\mu_{10}$ & 5 & 282.92100 & 141.55010 & 70.86611 & 47.30404 & 35.52296 & 28.45403 \\
& 10 & 283.09800 & 141.72600 & 71.03886 & 47.47403 & 35.68903 & 28.61505 \\
& 20 & 283.89300 & 142.07280 & 71.37132 & 47.78694 & 35.97911 & 28.88111 \\
& 40 & 284.14280 & 142.73980 & 71.95402 & 48.27415 & 36.38008 & 29.21006 \\
& 60 & 284.87300 & 143.34260 & 72.41243 & 48.60157 & 36.61469 & 29.38206 \\
& 80 & 285.47530 & 143.90650 & 72.76199 & 48.82077 & 36.75959 & 29.48341 \\
\hline
\end{tabular}

Table 2 Roots $\mu_{\text {of }}$ of characteristic equation (25)

\begin{tabular}{|c|c|c|c|c|c|c|c|c|c|c|c|c|c|}
\hline $\mathrm{k}_{\mathrm{o}}$ & 1.1 & 1.105882 & 1.2 & 1.3 & 1.4 & 1.5 & 1.6 & 1.7 & 1.8 & 1.9 & 2.0 & 3.0 & 4.0 \\
\hline 1 & 0 & 35 & 7.5663 & 9 & 45 & 2.0 & 2.3 & 2.0 & 1.13 & 1.5 & 1.3608 & 0.0 & 0.3935 \\
\hline & 4 & 33 & 88 & 15.0 & 72 & 48 & 7.7775 & 83 & 94 & 5.1 & 59 & 2. & 1.5266 \\
\hline & 78 & 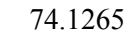 & & 2 & & & & & & & & & \\
\hline 4 & 109.9132 & 103.7941 & 54.9 & 36.6126 & 27.4 & 21.9570 & 18.2 & 15.6 & 13.7 & 12.1 & 10.9 & 5.4 & 3.6456 \\
\hline 5 & 141.3353 & 133.4832 & 70.6553 & 47.0947 & 35.3152 & 28.2472 & 23.5365 & 20.1711 & 17.6479 & 15.6850 & 14.1 & 7.0 & 4.6970 \\
\hline 6 & 172. & 163.1 & 86.3708 & 57.5 & 43. & 34.5348 & $28.7^{\prime}$ & 24.6 & 21.5792 & 19.1802 & 17.2607 & 8.6 & 5.7470 \\
\hline & 204. & 192 & 2 & 6 & 51 & 40. & & & & 22 . & 20. & & 6.7 \\
\hline 8 & 235.5 & 222.5 & 117. & 78.5 & 58.8 & 47.1 & 39.2 & 33.6 & 29.4 & 26.1 & 23.5 & 11 & 7.8447 \\
\hline 7 & 267.0 & 252.1756 & 133. & 88.9 & 66.7 & 53.3 & 44. & 38.1 & 33.3 & 29.6 & 26.6 & 13. & 8.8930 \\
\hline 0 & 298.4339 & 281.8564 & 149.2068 & 99.4693 & 74.5968 & 59.6776 & 49.7298 & 42.6254 & 37.2957 & 33.1505 & 29.8347 & 14.9144 & 9.9411 \\
\hline
\end{tabular}

$$
-\sigma_{T, \varphi}\left(r_{i n}, t_{i}\right) \cong \sigma_{a}, \quad i=1, \ldots, n_{t}
$$

Optimum fluid temperature changes during heating of the hollow cylinder will be calculated for $p=p_{o}$ and $p>p_{o}$.

The solution steps are depicted in the flow chart (Fig. 3).

When considering a vessel with holes, the method proposed in the paper may also be used for determining the optimum temperature of the fluid. In that case, the sum of squared differences of the calculated circumferential stress: $\sigma_{\varphi}=\sigma_{T, \varphi}+\sigma_{p}$ and allowable stress $\sigma_{a}$ for the selected $n_{t}$ time points at the point $\mathrm{P}$ of the maximum stress concentration on the hole edge should be minimum

$\sum_{i=1}^{n_{t}}\left[\int_{0}^{t_{i}} f(\theta) \frac{\partial u\left(\mathbf{r}_{P}, t-\theta\right)}{\partial t} d \theta+\alpha_{m}\left(p-p_{o}\right) \frac{2 r_{i n}+s}{2 s}-\sigma_{a}\right]^{2}=\min$

Fluid excess temperature $f(\theta)=T_{f}-T_{0}$ in the sum (34) can be assumed a function (29) or (30).

\section{Test calculations}

To illustrate the effectiveness of the proposed method test calculations have been carried out for a water separator of the supercritical boiler and for a drum installed in the boiler with natural circulation.

The following data were adopted for the water separator: $r_{i n}=0.255 \mathrm{~m}, r_{o}=0.315 \mathrm{~m}, \lambda=29.45 \mathrm{~W} /(\mathrm{mK})$; $c=513.75 \mathrm{~J} /(\mathrm{kgK}) ; \rho=7782.5 \mathrm{~kg} / \mathrm{m}^{3} ; E=2.07 \cdot 10^{11} \mathrm{~N} / \mathrm{m}^{2}$; $\beta=1.13 \cdot 10^{-5} 1 / \mathrm{K}$, and $v=0.3$. The heat transfer coefficient on the inner surface of the water separator was assumed to be: $\alpha=2000 \mathrm{~W} /\left(\mathrm{m}^{2} \mathrm{~K}\right)$. The pressure inside the vessel is equal to atmospheric pressure i.e. $p=p_{o}$. The first 12 roots of the characteristic equation (24) are: $\mu_{1}=5.12868$, $\mu_{2}=16.71547, \mu_{3}=28.98302, \mu_{4}=41.72671, \mu_{5}=54.71176$, $\mu_{6}=67.82378, \mu_{7}=81.00823, \mu_{8}=94.23722, \mu_{9}=107.49529$, $\mu_{10}=120.77334, \quad \mu_{11}=134.06564, \quad \mu_{12}=147.36846 . \quad$ A comparison of the influence function calculated analytically and using the FEM for the heat transfer coefficient equal to $\alpha=2000 \mathrm{~W} /\left(\mathrm{m}^{2} \mathrm{~K}\right)$ is shown in Fig. 4. The compatibility of the results is very good. Small differences between the results may be observed at the beginning of heating. This difference is mainly due to insufficient accuracy of the analytical solution (28) for small values of the time, in spite of the 12 terms in the series.

In order to assess the accuracy of the method, first the circumferential stress on the inner surface of the water separator was calculated using the FEM. The fluid temperature $T_{f}$ is given by the following formula

$$
T_{f}=80+0.2 t
$$

The calculated circumferential stress is shown in Fig. 5. Thus this circumferential stress is considered as a time dependent allowable stress $\sigma_{a}$. The allowable stress $\sigma_{a}\left(t_{i}\right)$ in (33) was given at 50 time points: $t_{i}=4+40.61(i-1), \quad i=1, \ldots, 50$. The allowable stresses are indicated in Fig. 5 by means of hollow circles. The optimum temperature determined from the condition (32) is illustrated in Fig. 5. The optimum fluid temperature

$$
T_{f}=79.9029+0.1999 t
$$




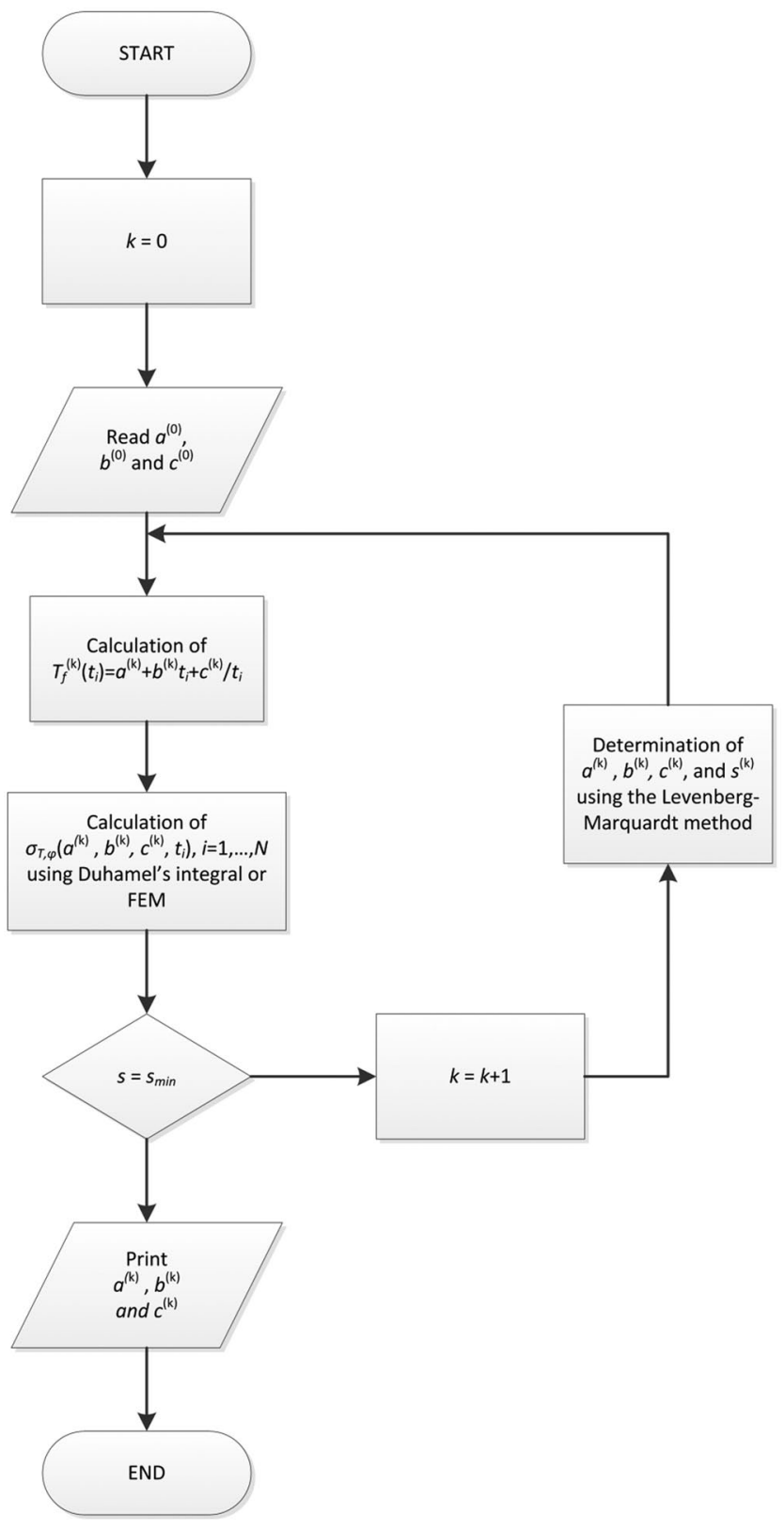

Fig. 3 Flow chart illustrating determination of the optimum fluid temperature, defined by the function (29)

coincides with the temperature (35) adopted for the solution of the direct problem (Fig. 5). In the next test calculation the optimum fluid temperature was determined from the condition (32) approximating fluid temperature changes by the function (29) or (30). In addition, the optimum fluid temperature was determined from the solution of the integral equation

$$
\sigma_{T, \varphi}=\sigma_{a}
$$

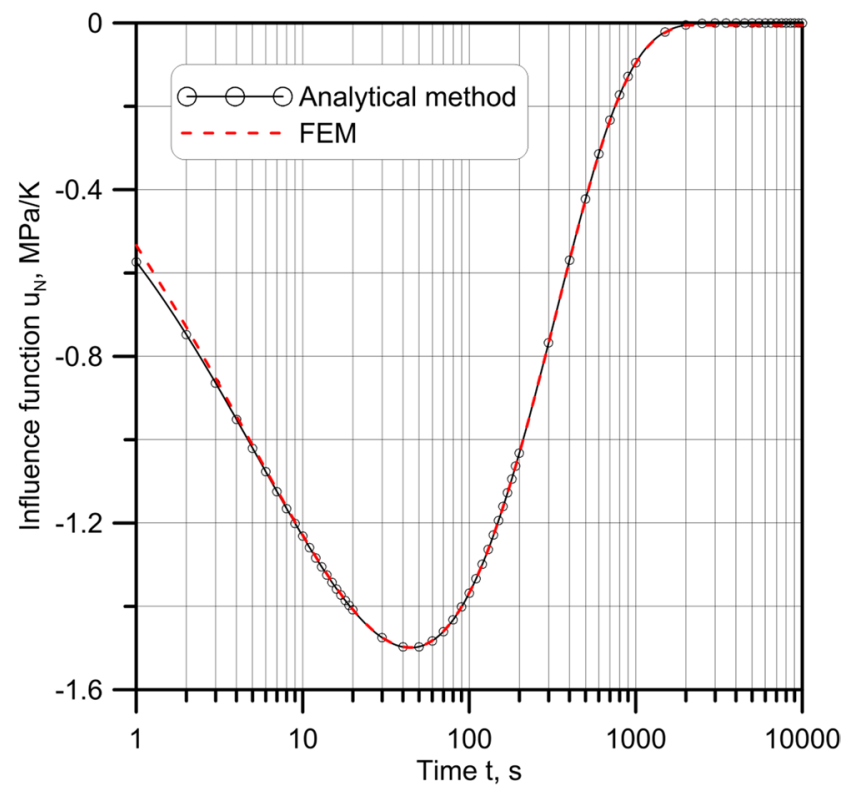

Fig. 4 Comparison of influence function for water separator calculated by analytical method and FEM for $\alpha=2000 \mathrm{~W} /$ $\left(\mathrm{m}^{2} \mathrm{~K}\right)$

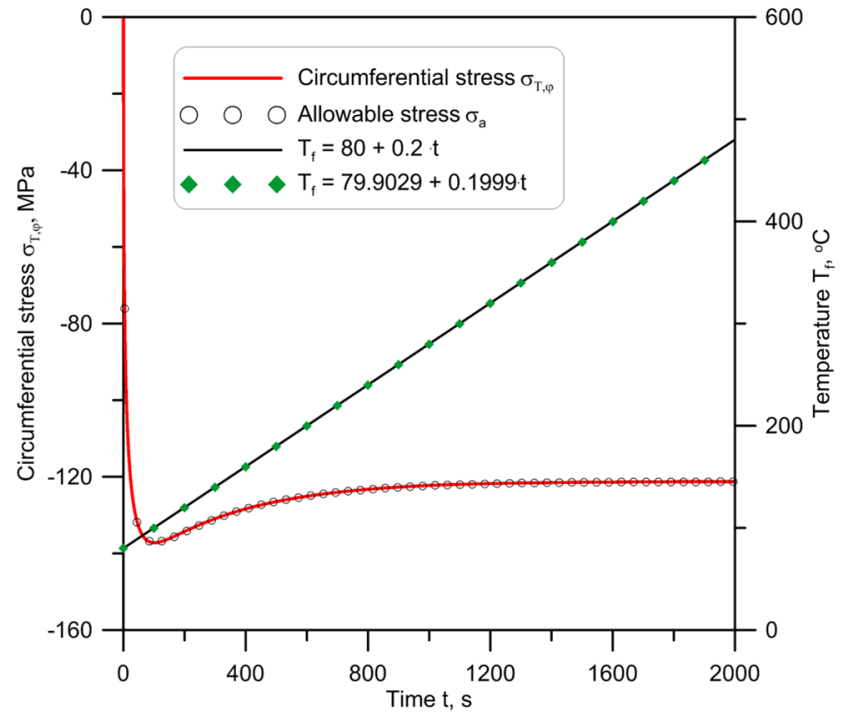

Fig. 5 Allowable stress and optimum fluid temperature for water separator

where the circumferential stress is given by the Duhamel integral (12). The method of rectangles was used to solve sequentially (37) [11]. The allowable stress $\sigma_{a}=-253.3 \mathrm{MPa}$ was determined using the European Standard EN 12952-3 assuming 2000 start-ups of the boiler from the cold state. The comparison of the results ilustrates Fig. 6. Larger differences between the optimum temperature runs occur only at the beginning of the heating process.

Next, optimum fluid temperature changes were estimated for a thick walled boiler drum. The dimensions of the 


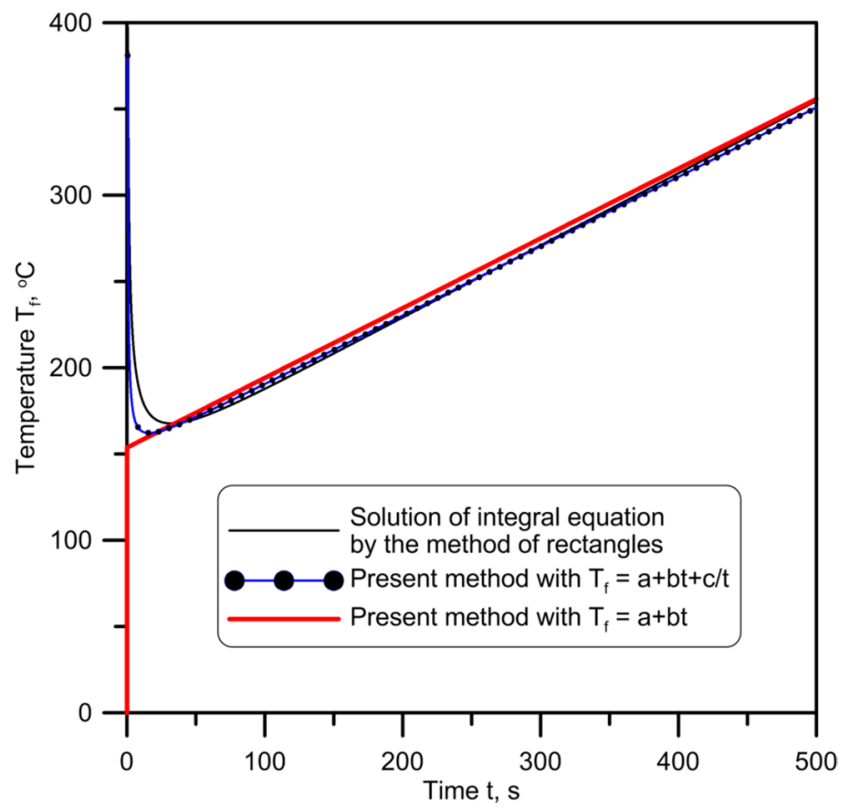

Fig. 6 Optimum fluid temperature during heating water separator for allowable circumferential stress equal to $-253.3 \mathrm{MPa}$

Table 3 Roots of characteristic equation (24) for the hollow cylinder for $k_{o}=r_{o} / r_{i n}=1.10588$

\begin{tabular}{lrrrrr}
\hline$\mu_{\mathrm{i}}$ & $\mathrm{Bi}=5$ & $\mathrm{Bi}=10$ & $\mathrm{Bi}=20$ & $\mathrm{Bi}=30$ & $\mathrm{Bi}=80$ \\
\hline$\mu_{1}$ & 6.16106 & 8.08822 & 10.08103 & 11.13402 & 12.98685 \\
$\mu_{2}$ & 31.17888 & 32.48773 & 34.59562 & 36.16588 & 40.03724 \\
$\mu_{3}$ & 60.12975 & 60.88211 & 62.27421 & 63.50099 & 67.51989 \\
$\mu_{4}$ & 89.54222 & 90.05928 & 91.05506 & 91.98782 & 95.57679 \\
$\mu_{5}$ & 119.08148 & 119.47360 & 120.24079 & 120.97858 & 124.08235 \\
$\mu_{6}$ & 148.67273 & 148.98807 & 149.60978 & 150.21570 & 152.90117 \\
$\mu_{7}$ & 178.29025 & 178.55378 & 179.07559 & 179.58799 & 181.93378 \\
$\mu_{8}$ & 207.92287 & 208.14914 & 208.59835 & 209.04154 & 211.11394 \\
$\mu_{9}$ & 237.56494 & 237.76315 & 238.15733 & 238.54742 & 240.39827 \\
$\mu_{10}$ & 267.21334 & 267.38966 & 267.74072 & 268.08890 & 269.75803 \\
$\mu_{11}$ & 296.86616 & 297.02494 & 297.34134 & 297.65563 & 299.17378 \\
$\mu_{12}$ & 326.52222 & 326.66666 & 326.95455 & 327.24089 & 328.63202 \\
\hline
\end{tabular}

drum are: inner radius $r_{i n}=850 \mathrm{~mm}$ and wall thickness $s=90 \mathrm{~mm}$. The following properties of steel were adopted for the calculation: $\lambda=47.3 \mathrm{~W} /(\mathrm{mK}) ; c=511 \mathrm{~J} /(\mathrm{kgK})$; $\rho=7775 \mathrm{~kg} / \mathrm{m}^{3} ; E=2.07 \cdot 10^{11} \mathrm{~N} / \mathrm{m}^{2} ; \beta=1.13 \cdot 10^{-5} 1 / \mathrm{K}$, and $\nu=0.3$. Allowable stress is: $\sigma_{a}=-68 \mathrm{MPa}$. To calculate the influence function $u_{N}(t)$ for various Biot numbers the first twelve roots of (24) were determined (Table 3 ). Time changes of the influence function for various Biot numbers obtained using the analytical solution (26) and the Finite Element Method (FEM) are compared in Fig. 7. The heat transfer coefficient on the inner surface of the drum was assumed to be: $\alpha=1000 \mathrm{~W} /\left(\mathrm{m}^{2} \mathrm{~K}\right)$. First, optimum fluid temperature were estimated by solving overdetermined system of nonlinear algebraic equations (33). At every time step, the

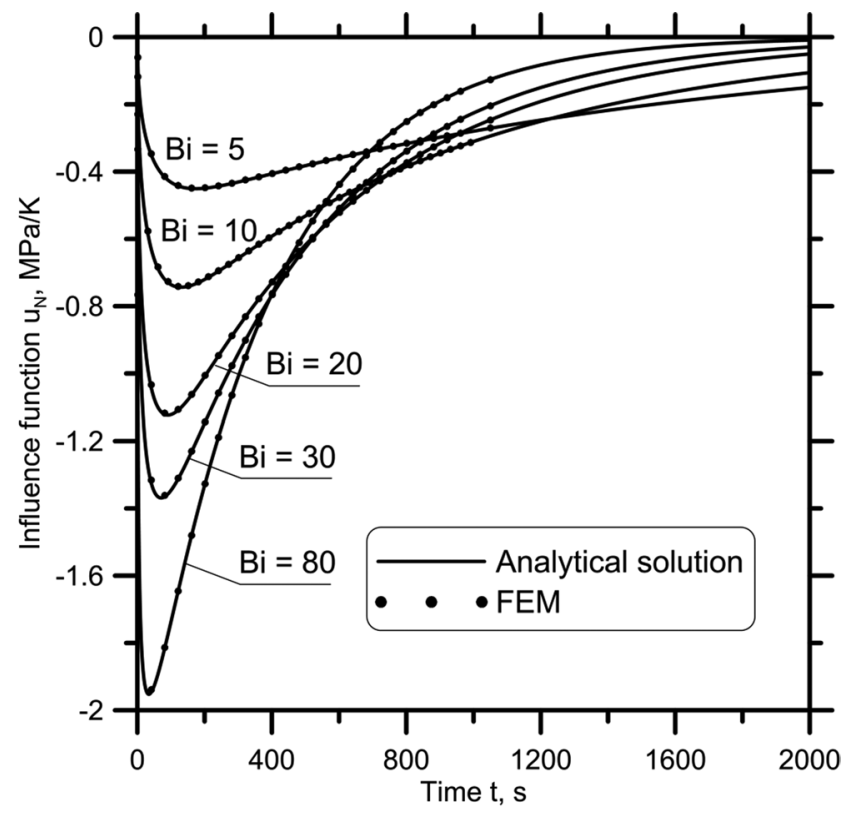

Fig. 7 Comparison of influence function $u_{N}$ for boiler drum calculated by analytical method and FEM

Table 4 Optimum temperature changes during heating of the hollow cylinder

\begin{tabular}{llllllll}
\hline Bi & & \multicolumn{3}{c}{$T_{f}=T_{0}+a+b t+c / t$} & & \multicolumn{2}{c}{$T_{f}=T_{0}+a+b t$} \\
\cline { 3 - 4 } \cline { 7 - 8 } & & $a, \mathrm{~K}$ & $b, \mathrm{~K} / \mathrm{s}$ & $C, \mathrm{~K} \cdot \mathrm{s}$ & & $a, \mathrm{~K}$ & $b, \mathrm{~K} / \mathrm{s}$ \\
\hline 5 & FEM & 137.4 & 0.0832 & 528.6 & & 140.1 & 0.0826 \\
& Analytical & 136.18 & 0.0834 & 484.8 & & 139.28 & 0.0824 \\
10 & FEM & 80.79 & 0.0833 & 261.72 & & 82.39 & 0.0830 \\
& Analytical & 79.93 & 0.0834 & 239.33 & & 82.35 & 0.0821 \\
20 & FEM & 52.54 & 0.0834 & 128.45 & & 53.54 & 0.0832 \\
& Analytical & 51.81 & 0.0834 & 117.83 & & 53.32 & 0.0826 \\
30 & FEM & 43.13 & 0.0835 & 84.22 & & 43.85 & 0.0833 \\
& Analytical & 42.43 & 0.0834 & 77.60 & & 43.80 & 0.0823 \\
80 & FEM & 31.21 & 0.0836 & 29.76 & & 31.41 & 0.0835 \\
& Analytical & 30.68 & 0.0834 & 28.13 & & 31.21 & 0.0830 \\
\hline
\end{tabular}

circumferential stress at the inner surface was calculated using discrete form of the Duhamel integral. The unknown parameters $a, b$, and $c$ in function (29) or parameters $a$ and $b$ in function (30) were determined by the least squares method applying the Levenberg- Marquardt method. In the second approach thermal stresses were computed using the Ansys software [22] without introducing the influence function. Thermal stresses at the cylinder inner surface were calculated for given time points using the FEM method at every iteration step of the Levenberg-Marqardt algorithm. The optimum fluid temperature changes are shown in Figs. 8 and 9. In adition, the optimum parameter values appearing in the functions (29) and (30) are given in Table 4. The analysis of the results shown in Figs. 8 and 9 indicates 


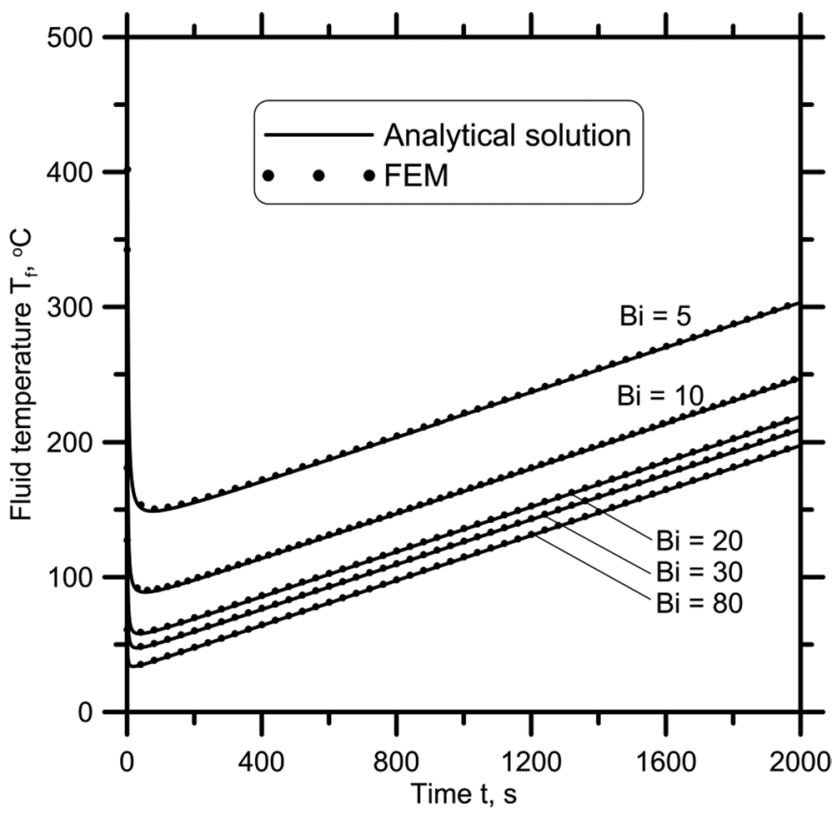

Fig. 8 Comparison of optimum fluid temperature changes for boiler drum approximated by function (29) using the Duhamel integral and FEM

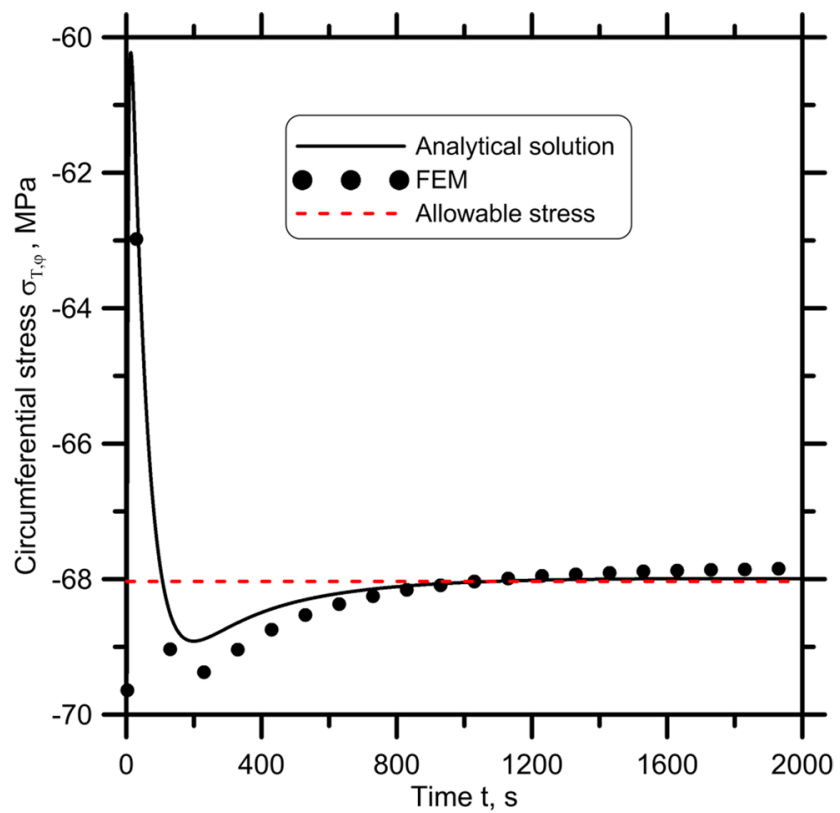

Fig. 10 Comparison of the calculated and allowable circumferential stress during optimum heating of the boiler drum-fluid temperature given by three parameter function (29)

that optimum temperature changes determined by the both described methods differ slightly. During optimum heating the circumferential thermal stresses at the inner surface are equal approximately the allowable value (Figs. 10 and 11). If the optimum temperature is approximated by the function (29) containing two unknown parameters then the agreement between the calculated and the allowable stress

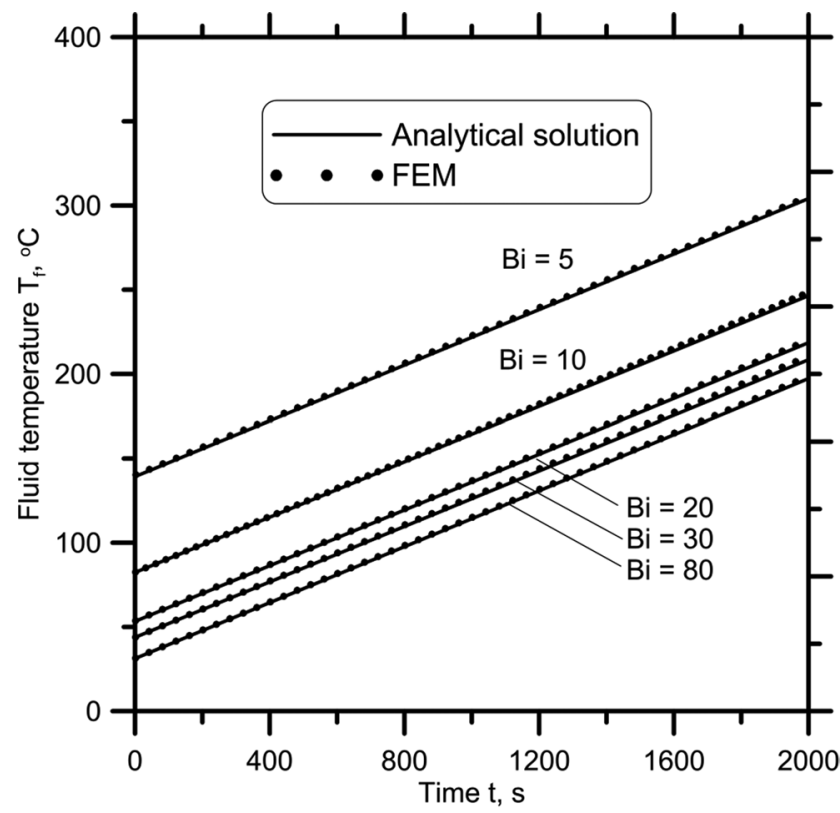

Fig. 9 Comparison of optimum fluid temperature changes for boiler drum approximated by function (30) using the Duhamel integral and FEM

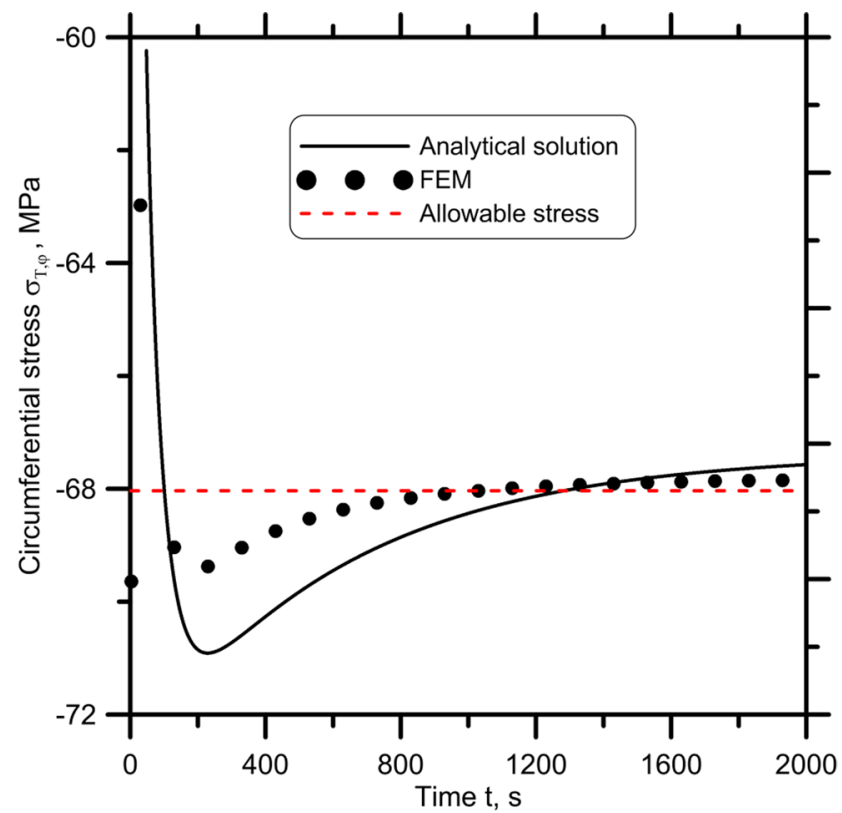

Fig. 11 Comparison of the calculated and allowable circumferential stress during optimum heating of the boiler drum - fluid temperature given by two parameter function (30)

is better (Fig. 10) in comparison with two parameter curve given by the function (30). The discrepancy between the calculated and allowable stress is larger at the beginning of the heating process (Fig. 11). The form of the optimum temperature change given by (30) is to simple to make calculated circumferential stress equal to the allowable value. However, the fluid time temperature changes resulting 


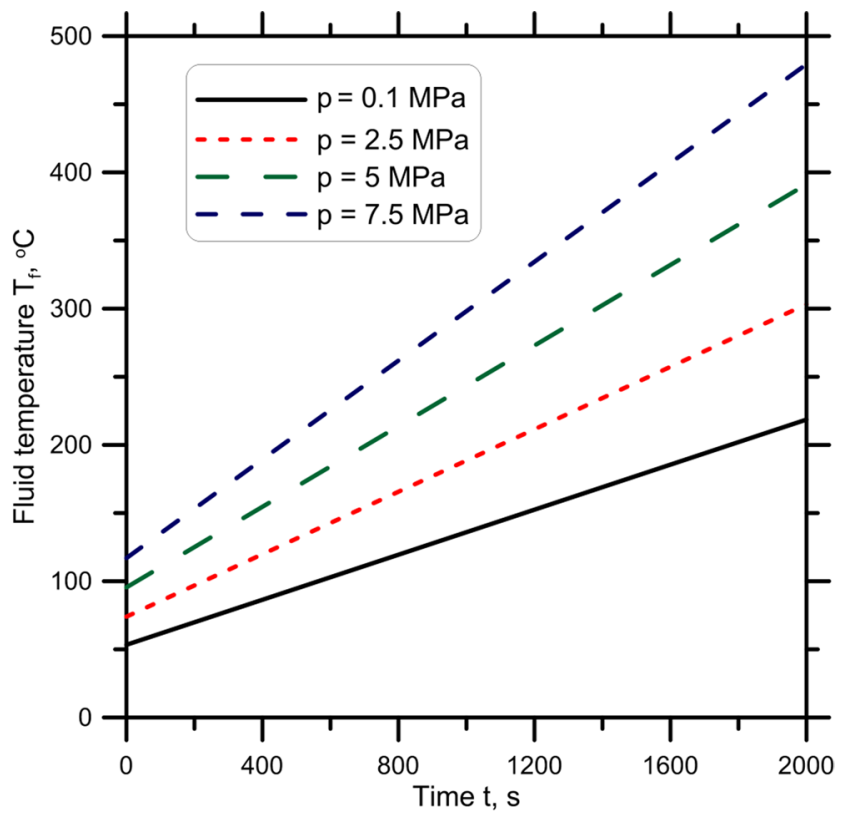

Fig. 12 Influence of inner pressure on optimum heating of the boiler drum

from (30) can be easily conducted in the practice. Fig. 12 illustrates the influence of the inner pressure on optimum fluid temperature changes. With increasing pressure the initial stepwise temperature increase, as well as, the heating rate $v_{T}$ goes up.

\section{Conclusions}

Two methods for determining optimum fluid temperature changes during heating of the hollow cylinder were presented. During optimum heating of the cylinder the circumferential thermal stress at the inner surface of the cylinder is equal to the allowable value. Optimum fluid temperature was approximated by simple functions. Unknown parameters appearing in these functions were estimated using the Levenberg-Marquardt method. The circumferential thermal stress was evaluated using the Duhamel integral or the Finite Element Method. Both methods give almost identical results. Since the influence function is calculated from an exact analytical solution, the first method based on the Duhamel integral method can be used to assess the accuracy of numerical solutions, for example solutions obtained by the FEM. When the FEM is used to compute thermal stresses then time optimum fluid temperature changes may be determined for temperature dependent physical material properties and complex form of the construction element can easily be accounted for.

\section{Compliance with Ethical Standards}

Conflict of interest The authors declare that there are no actual or potential conflicts of interest in relation to this article.

Open Access This article is distributed under the terms of the Creative Commons Attribution License which permits any use, distribution, and reproduction in any medium, provided the original author(s) and the source are credited.

\section{References}

1. Rop P (2010) Drum Plus: a drum type HRSG with Benson benefits. Mod Pow Syst 30:35-40

2. Staff report (2007) Dealing with cycling: TRD 301 and Euro Norm compared. Mod Pow Syst 27:33-38

3. Taler J (1997) Überwachung von instationären Wärmespannungen in dickwandigen Bauteilen. Forsch Ingenieurwes 63:127-135

4. Krüger K, Franke R, Rode M (2004) Optimization of boiler startup using a nonlinear boiler model and hard constraints. Energy 29:2239-2251

5. Kim TS, Lee DK, Ro ST (2000) Analysis of thermal stress evolution in the steam drum during start-up of a heat recovery steam generator. Appl Therm Eng 20:977-992

6. Kehlhofer R, Hannemann F, Stirnimann F, Rukes B (2009) Combined-cycle gas and steam turbine power plants, 3rd edn. PennWell Corporation, Tulsa

7. EN 12952-3 Water-tube boilers and auxiliary installations-Part 3: design and calculation for pressure parts. European Committee for Standardization, Brussele

8. Dzierwa P (2013) Quasi-steady-state approach for solving transient heat conduction problems. In: Hetnarski R (ed) Encyclopedia of thermal stresses. Springer, Berlin (in print)

9. Haneke R, Speitkamp L (1987) Optimierung dickwandiger Kesselbauteile im Hinblick auf kurze An- und Abfahrzeiten. VGB Kraftwerkstechnik 67(9):858-862

10. Taler J, Dzierwa P, Taler D (2009) Optimum heating of pressure components of large steam boilers. Forsch Ingenieurwes 73(3):183-192

11. Taler J, Dzierwa P (2011) A new method for optimum heating of steam boiler pressure components. Int J Energy Res 35:897-908

12. Dzierwa P (2013) Optimum heating of pressure components of complex shape. In: Hetnarski R (ed) Encyclopedia of thermal stresses. Springer, Berlin (in print)

13. Taler D, Taler J (2009) Optimum heating of thick plate. Int J Heat Mass Transf 52(9-10):2335-2342

14. Timoshenko SP, Goodier JN (1970) Theory of elasticity. McGrawHill, New York

15. Parkus H (1976) Thermoelasticity. Springer, New York

16. Carslaw HS, Jaeger JC (2000) Conduction of heat in solids, 2nd edn. Oxford University Press, New York

17. Taler J, Duda P (2006) Solving direct and inverse heat conduction problems. Springer, Berlin

18. Schweigerer S (1978) Festigkeitsberechnung im Dampfkessel-, Behälter- und Rohrleitungsbau. Springer, Berlin

19. Elizarov DP (1971) Thermal shock in steam lines of thermal power stations. Tieploenergetika (Thermal Engineering) 18(2):78-82

20. The IMSL Fortran 90 MP mathematics and statistics libraries (F90 MP). Visual Numerics Inc., Houston

21. Press WH, Teukolsky SA, Vetterling WT, Flannery BP (2008) Fortran numerical recipes, 2nd edn. Cambridge University Press, Cambridge

22. Ansys, Release 13.0, ANSYS, Inc., Southpointe, 275 Technology Drive, Canonsburg 